\title{
Farewell Editorial
}

\author{
Sergey Foss ${ }^{1,2}$
}

Received: 18 December 2021 / Revised: 19 December 2021 / Accepted: 19 December 2021 /

Published online: 7 January 2022

(c) The Author(s), under exclusive licence to Springer Science+Business Media, LLC, part of Springer Nature 2022

I have served as Editor-in-Chief of QUESTA for twelve years (2010-2021) and, before that, co-edited the journal with Onno Boxma in 2009. This is the right time to step down-especially because this Editorial appears in Volume 100! I am delighted to announce that Michel Mandjes has agreed to take over the editorship. Michel is one of the leading experts in stochastic processes and their applications, including queueing, communication, traffic and service systems, networks and corresponding simulation methodology. His contribution to QUESTA is most impressive. He is one of the most active authors of the journal, with 35 published papers, and is a very active referee. He has been an associate editor since 2006 and the guest editor of three special issues. I believe his leadership will bring a new impulse to the further development of the journal.

I would like to thank all colleagues who have contributed to the journal's performance and success over the years and, in particular, during the time of my editorship. The friendly support and guidance and the expert advice of the Advisory and Editorial Boards have been a constant help to me, both in the everyday work of editing the journal and on a number of special occasions.

Below are the lists of the members of the Editorial and Advisory Boards, of the Special Issues and of the most active reviewers within 2010-2021. An interesting analysis of the papers published in QUESTA in 1986-2021 will appear in one of the next volumes.

Appendix (A). Lists of members of the Editorial and Advisory Boards whose periods of service have overlapped with my editorship of the journal (2010-21).

Lists of the 1986, 1996, 2004 Editorial Boards may be found in my Editorial from 2010 (Volume 64, pp.1-3), DOI 10.1007/s11134-009-9156-3

Sergey Foss

sergueiorfoss25@gmail.com

1 Edinburgh, United Kingdom

2 Novosibirsk, Russia 
EDITORIAL BOARDS (2010-21):

I.Adan (2004-21), R.Atar (2010-13), J.Blanchet (2009-18), S.Borst (2009-21), A.Brandt (1998-2013), K.Debicki (2010-21), A.Economou (2019-21), D.Gamarnik (2010-11), A.J.Ganesh (2009-21), K.D.Glazebrook (2002-15), D.A.Goldberg (201621), J.Hasenbein (2008-21), M.Harchol-Balter (2019-21), J.Ivanovs (2019-21), R.Jain (2019-21), M.Jonckheere (2016-21), I.Kaj (2009-21), O.Kella (1995-2021), T.Konstantopoulos (1995-2011), D.Korshunov (2010-21), S.Kumar (2010), M.Lelarge (2012-18), N.Litvak (2019-21), J.Mairesse (2010-18), M.Mandjes (2006-21), D.Manjunath (2014-15), M.Mijazawa (1993-2021), P.Momcilovic (2012-21), P.Moyal (2019-21), Y.Nazarathy (2020-21), G.T.Nguyen (2019-21), I.Norros (2010-21), M.Olvera-Cravioto (2014-21), G.Pang (2014-21), D.Perry (2000-18), O.Perry (201921), A.Proutíere (2010-15), A.Puhalskii (2009-15), R.Righter (2000-09 and 201621), Ph.Robert (2009-21), S.Schakkotai (2014-18), A.Scheller-Wolf (2012-18), D.Shah (2012-13), S.Shneer (2016-21), F.Simatos (2016-21), A.Stolyar (2009-21), T.Takine (2005-13), L.Tassiulas (2010-11), P.Taylor (1997-2021), P.Thiran (2010-11), J.S.H. van Leeuwaarden (2012-15), A.Wierman (2014-18), S.Zachary (2004-2015), Y.Q.Zhao (2000-21), I.Ziedins (2011-21), S.Ziya (2016-19), S.Zuyev (2009-13), B.Zwart (2008-21).

ADVISORY BOARDS (2010-21):

V.Anantharam (advisor 2012-21, editor 1989-2011), S.Asmussen (advisor 2009-21, editor 1994-2008), F.Baccelli (advisor 2009-21, editor 1993-2008), O.J.Boxma (advisor 2010-21, EiC 2004-09, editor 1986-2003), P.W.Glynn (advisor 2010-21), F.P.Kelly (advisor 2009-11, editor 1995-2008), K.Ramanan (advisor 2019-21, editor 20082018).

\section{Appendix (B). List of Special Issues in 2010-21.}

2011. Open Problems (M.Mandjes, Z.Palmowski, and S.Shneer).

2011. Progress in Stochastic Networks (J.Martin, K.Ramanan, and T.Konstantopoulos).

2012. Mathematical Challenges in Stochastic Networks (G.Last, M.Mandjes, and S.Zuyev).

2012. Mathematics of Resource Sharing in Computer and Communication Systems (P.Barford, S.Borst, and M.S.Squillante).

2012. Recent Trends in the Mathematics of Wireless Communication Networks: Algorithms, Models and Methods (S.Borst, A.Proutíere, and D.Shah; in two parts).

2013. Stochastic Networks: Tail Asymptotics for Stationary Distributions and Related Topics (M.Miyazawa and Y.Q.Zhao).

2013. Queueing Systems with Abandonments (J.Hasenbein and D.Perry).

2014. The Boris V. Gnedenko Centennial (L.G.Afanasyeva, D.Korshunov, and D.Shabanov).

2014. Stochastic models for performance analysis: memory, power, and delays (A.B.Dieker and M.Lelarge).

2015. Queues in Health (R.J.Boucherie and I.J.B.F.Adan).

2015. ACM SIGMETRICS 2014 (M.Lelarge and F.Simatos). 
2016. Methodological Advances in Queueing Theory - The First ECQT conference (O.J.Boxma and J.Walraevens).

2016. ACM SIGMETRICS 2015 (A.Ganesh and F.Simatos).

2017. Current Trends in Queueing Theory - The Second ECQT conference (R.Righter and I.M.Verloop; in two parts).

2018. ACM SIGMETRICS - 2016 (T.Bonald and A.Ganesh).

2018. In honour of Ward Whitt reaching 75 (A.Ward and G.Pang).

2019. Performance Evaluation - 2018 (M.Mandjes and Ph.Robert).

2019. Stochastic Networks 2018 (F.Daly and S.Shneer).

2019-20. Recent Developments in Queueing Theory - The Third ECQT conference (I.J.B.F.Adan, B.D’ Auria, and O.Kella; in two parts).

2020. Analytical and Computational Methods in Probability (D.Korshunov and A.Veretennikov).

2020-21. Strategic Queueing: Game-theoretic Models in Queueing Theory (A.Economou and V.Kulkarni; in two parts).

2020. Stochastic Matching Models, Matching Queues and Applications (J.Mairesse and P.Moyal).

2020-21-22. Modern Trends in Applied Probability (Collection of Invited papers, related to Applied Probability INFORMS conference 2019, R.McVinish, Y.Nazarathy, and G.Nguyen).

2021. Workshop 'Modern Applied Probability' (T.Konstantopoulos and D.Korshunov).

\section{Appendix (C). The list of most active reviewers.}

The list includes the names of colleagues who have refereed 6 or more papers within 2010-21. It is started with the 10 top reviewers. Then, all other names are given in alphabetical order. I would like to thank Mangayarkarasi Lakshmiram (Springer assistant) for providing the list.

The top 10:

M.Miyazawa (29 papers), I.Kaj (22), Ph.Robert (20), A.Economou (19), D.Korshunov (17), M.Jonckheere (17), S.Borst (16), P.Momcilovic (14), G.Pang (13), P.Moyal (13).

The list of other colleagues who reviewed 6 papers or more:

S.Aalto, K.Avrachenkov, U.Ayesta, H.Ayhan, R.Bekker, M.Boon, O.J.Boxma, B.d'Auria, J.Dong, S.Doroudi, D.Down, A.Ganesh, D.Goldberg, F.Guillemin, V.Gupta, I.Gurvich, J.Hasenbein, R.Hassin, W.Kang, S.Kapodistria, Y.Kerner, B.Kim, Y.Kocaga, G.Latouche, Y.Liu, J.Mairesse, M.Mandjes, Y.Nazarathy, L.Ormeci, B.Oz, O.Perry, T.Phung-Duc, A.Proutíere, A.Puhalskii, L.Ravner, J.Reed, J.Resing, S.Shneer, P.Taylor, M.Telek, N.Walton, A.Ward, U.Yechali, Y.Q.Zhao, Y.Zhong, I.Ziedins.

Publisher's Note Springer Nature remains neutral with regard to jurisdictional claims in published maps and institutional affiliations. 